carried out by the above firm, the length of the piston bar $B$ is increased or diminished at will, and thereby the strength of the pump is regulated.

\section{COMPLETE APPARATUS FOR VENOUS AND SUB- CUTANEOUS INFUSION IN STERILISER, WITH IMPROVED VENOUS INFUSION CANNULA.}

$\mathrm{By}$ the use of this cannula the chief disadvantage of the ordinary one, that it cannot with safety be left in situ in case further infusion should be necessary, is obviated. Before inserting into the vein the cannula is flushed throngh and filled in the ordinary way, the tap afterwards being

\section{FIG. 1.}

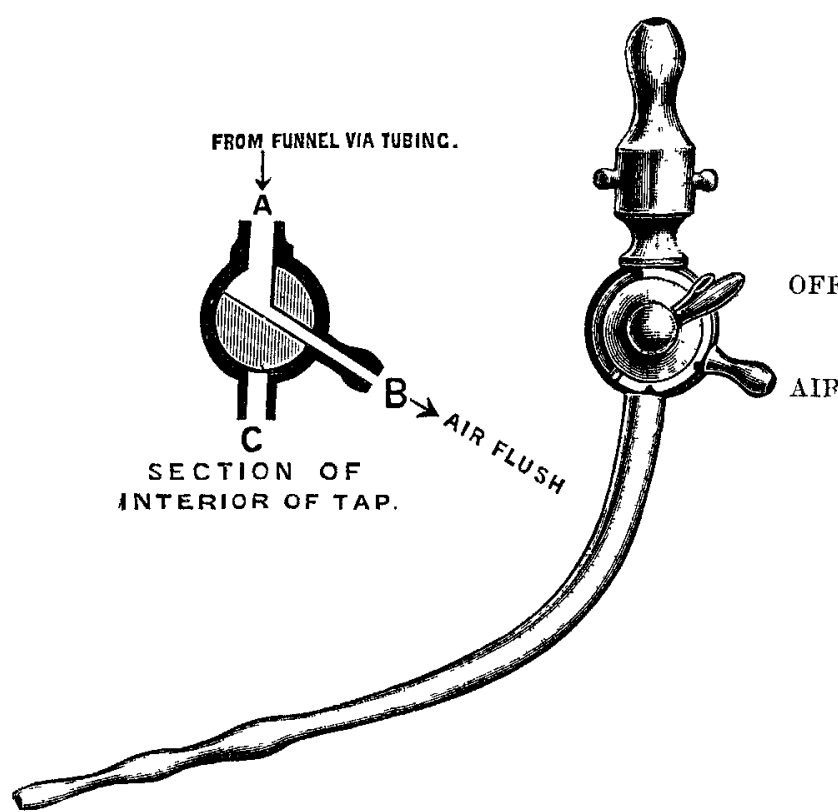

turned to "off." When the nozzle has been tied into the vein the tap is turned to the intermediate nozzle labeled "air" to see that the stream is flowing well and then full on, directing the solution into the vein. When as much as is required for the time being has been infused the tap is turned "off," the top joint to which the tube is attached is unscrewed, and the cannula is secured to the arm wrapped in a little gauze. If further infusion should be necessary the tube is again screwed on to the cannula, the funnel is filled, and the tap is turned to "air." all the air contained in the tube and upper part of the cannula being then flushed out. As soon as a good stream is flowing the tap is turned full on and the solution is directed into the vein. It will be noticed that a spring arrangement indicates when the various "stops" are reached. The nozzle has three bulbs of different sizes so that one cannula is suitable for any sized vein. The complete apparatus contains a fourounce glass funnel, six feet of rubber tubing, a silver venous cannula, a subcutaneous infusion needle, a solid forged

FIG. 2.

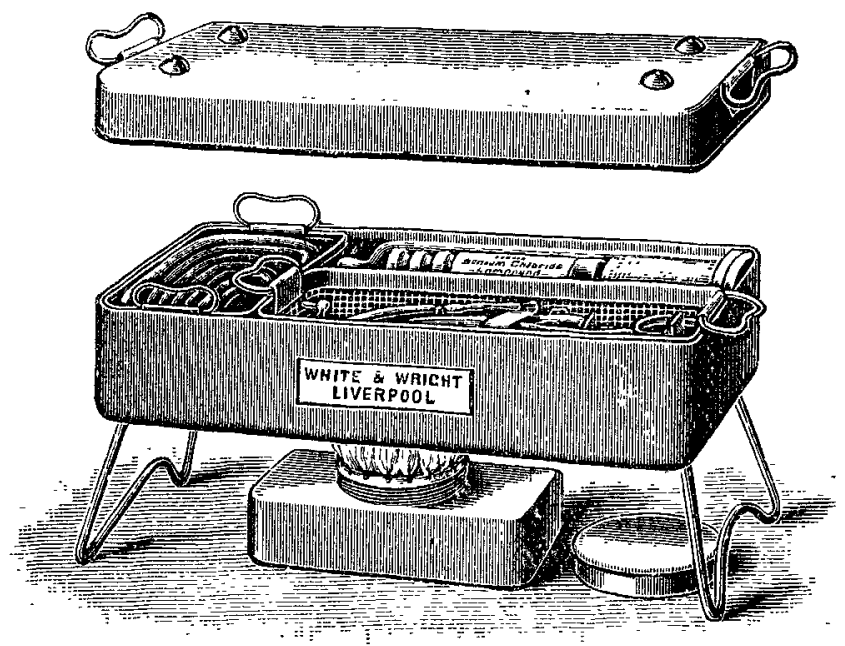

scalpel with blunt dissector end, st solid forged aneurysm needle, aseptic scissors, aseptic dissecting forceps, a metal tube containing needle and silk, a tube of saline tabloids, gauze for dressing, aseptic sponges, and a bandage. The steriliser measures eight inches by four inches by one and a half inches. The advantages claimed for the "set" are: (1) all the instruments and appliances actually required for venous infusion are kept ready to hand in a steriliser in which they can be carried and boiled immediately, the bandage and tube of tabloids only being removed; and (2) since rubber blackens instruments when boiled with them the tubing is boiled separately in the steriliser in the box compartment, which contains the lamp while in transit. This cannula and infusion apparatus have been made by Messrs. White and Wright, 93, Renshaw-street, Liverpool, according to my directions. W. BLAIR BELI, M.D., B.S. Lond., Liverpool. M.R.C.S. Eng.

\section{A NEW 'THERMO-CAUTERY.}

THE maker and inventor of this new thermo-cautery is Mr. W. H. Beach, of Bridgnorth, Salop, who supplies it for the inclusive price of $105 \mathrm{~s}$. He states that being present

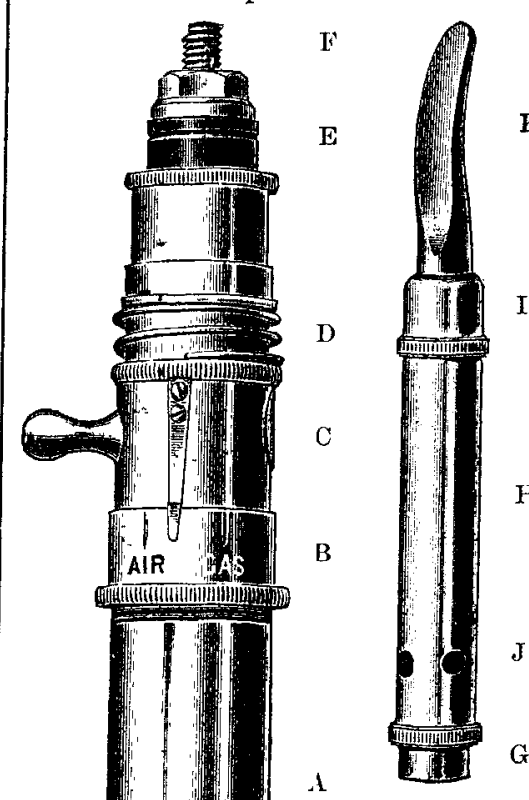
upon one occasion while a Paquelin cautery was in use, the accidental up. setting of the bottle containing the hydrocarbon occurred and convinced him that there were risks in using the apparatus. He therefore decided to devise a cautery in which the bottle could be dispensed with. The Beach cautery consists of the following parts. A stem or handle A acting as a combined reservoir and vaporiser; this chamber is lined with cotton wick which absorbs sufficient hydrocarbon (three quar ters of an ounce) to work the cautery continously for one hour. A trunk B com prising an aerator, refrigerator, and stopcock, and collar c, kept to its seat by a spring $\mathrm{D}$; this collar carries the index and air nipple, the latter forming an attachment for the bellows tube. A heat-resisting block $\mathrm{E}$, novel in construction, superimposes a wire gauze septum which prevents lighting back within this block is a connecting standard $F$, to which the working points are screwed; these latter are of course detachable, and are made up of a connecting boss $\mathrm{Gr}$ carrying the central supply-tube and the outer case $\mathrm{H}$, which supports the combustion chamber, at the same time forming a flue to the exhaust orifices J. The platinum supply tube as well as the combustion chamber $\mathrm{K}$ are mounted with a screw cap I in place of the old method of soldering. The hollow metal handle has, it will be seen, tubes projecting inwardly from the top. The tubes terminate near the centre of the handle which is lined with cotton wick and forms a reservoir and vaporiser, the gaseous mixture being at the same time aerated in such a way that the proportion of gas and air can be regulated with great nicety. The instrument can be raised to a white heat in half a minute, and similarly by allowing a blast of cold air to force its way in the heated portion of the instrument can be expeditiously cooled. The heat-resisting block, which with the septum renders it impossible for the gaseous mixture to light back and explode, is constructed of ebony with mica washers above and below, the bore in the ebony being greater than that of the standard, so that there is no metallic contact with the block. We have employed the cautery in treatment and find it very handy. The platinum point is easily raised to, and kept at, the desired temperature, when by a little practice the method of working the instrument has been learned. The absence of the benzene bottle is a great convenience. 